\title{
CARCINOEMBRYONIC ANTIGEN LEVELS IN THE PERIPHERAL AND MESENTERIC VENOUS BLOOD OF PATIENTS WITH RECTAL CARCINOMA
}

\author{
Herminio Cabral de REZENDE JUNIOR ${ }^{1}$, Rogério Tadeu PALIMA', Giovanna Canato TOLOI², \\ Carlos Augusto Real MARTINEZ ${ }^{3}$ and Jaques WAISBERG ${ }^{1}$
}

\begin{abstract}
Context - The serum carcinoembryonic antigen (CEA) is an important prognostic factor in colorectal cancer, however the rectum presents different routes of venous drainage, stating that the level of CEA in peripheral and mesenteric rectal tumors may be different, depending on the location of the tumor in the rectal segment. Objective - The goal of this study was to evaluate the relationship between the peripheral and mesenteric venous levels of CEA and the association between these levels and the tumour location in the rectums of patients successfully operated on for rectal carcinoma. Methods - Thirty-two patients who were surgically treated for rectal carcinoma were divided into patients with tumours located in the upper rectum $(\mathrm{n}=11)$ or lower rectum $(\mathrm{n}=21)$. The CEA values were assessed by electrochemiluminescence immunoassay. Serum and mesenteric CEA levels were associated with the tumour anatomopathological characteristics: location, histological type, cellular differentiation grade, depth of invasion into the rectal wall, angiolymphatic invasion, tumour, node, and metastasis staging; and the CEA index ( $\leq 1.0$ or $\geq 1.0 \mathrm{ng} / \mathrm{mL})$. Results Analysis of the serum CEA values using clinical and anatomopathological parameters revealed no significant association with tumour location, histological type, cellular differentiation grade, depth of invasion into the intestinal wall, and tumour, node, and metastasis staging. The mesenteric CEA levels were significantly associated with the tumour location $(P=0.01)$. The CEA values in the mesenteric venous blood and the presence of angiolymphatic invasion $(P=0.047)$ were significantly different. A significant relationship was found between the CEA index value and the rectal tumour location $(P=0.0001)$. Conclusions - The CEA levels were higher in the mesenteric vein in tumours located in the upper rectum and in the presence of angiolymphatic invasion. CEA drainage from lower rectum adenocarcinomas preferentially occurs through the systemic pathway.
\end{abstract}

HEADINGS - Rectal neoplasms. Carcinoembryonic antigen. Neoplasm metastasis.

\section{INTRODUCTION}

Colorectal cancer (CRC) is the third most common type of neoplasia worldwide, with approximately one million new cases annually, accounting for half a million deaths ${ }^{(7)}$. Mortality rates have not decreased significantly in recent decades, despite advances in diagnosing CRC and its metastases and improved surgical techniques and postoperative care. New monitoring strategies, such as magnetic resonance imaging (MRI) and positron emission tomography-computed tomography (PET-CT), have been proposed; however, carcinoembryonic antigen (CEA) remains the most common tumour marker for CRC monitoring, especially after tumour resection with curative intent $t^{(4,9)}$.

Although it is important as an independent prognostic variable and in postoperative monitoring, serum CEA collected from peripheral blood may be affected by marker production in tumour cells, release into tumour-adjacent tissues, metabolism and hepatic excretion, reabsorption through the colorectal wall, haemodilution, formation of immune complexes by antigen-antibody type reactions, and penetration of CEA into the blood and lymphatic systems ${ }^{(1,20)}$.

Most studies comparing the peripheral and mesenteric venous CEA levels in CRC jointly considered patients with colon or rectal tumours ${ }^{(6,17,18,21)}$. However, unlike the colon, the rectum has two main venous drainage pathways. In the upper rectum, the venous drainage occurs through the mesenteric veins (similar to tumours that are located in the colon) and, consequently, by the portal system. Conversely, the venous drainage of tumours located in the lower rectum occurs via the internal pudendal vein, a tributary of the internal iliac vein, and ultimately reaches the inferior vena cava ${ }^{(14)}$. The two rectal venous drainage

Departamento de Cirurgia, Faculdade de Medicina do ABC, Santo André, SP, Brasil; ${ }^{2}$ Faculdade de Medicina do ABC, Santo André, SP, Brasil; ${ }^{3}$ Departamento de Cirurgia, Faculdade de Medicina São Francisco, Bragança Paulista, SP, Brasil.

Correspondence: Rogério Tadeu Palma. Rua Padre Manoel de Paiva 264, ap.32 - 09070-230 - Santo André - São Paulo, SP, Brasil. E-mail: rogeriopalma@yahoo.com 
systems communicate through the intramural veins located in the rectal wall submucosa ${ }^{(10)}$.

These different venous drainage pathways might explain why tumours in the distal third of the rectum (lower rectum) and anal canal predominantly produce systemic metastases especially in the lungs rather than liver metastases ${ }^{(13)}$, while those in the upper rectum exhibit hepatic dissemination more frequently than dissemination to the lung.

Considering the existence of various rectal venous drainage pathways, the mesenteric and peripheral venous CEA levels in patients with rectal tumours may be different, depending on the rectal tumour height. Thus, tumours located in the middle and upper rectum, where the venous drainage occurs via the superior rectal vein, may have higher CEA levels in the portal circulation, whereas lesions located in the lower rectum may have lower portal vein CEA levels because they drain primarily into the largest venous contingent into the inferior vena cava system. To our knowledge, no studies have analysed the relationship between the rectal tumour location and the peripheral and mesenteric CEA venous drainage in patients submitted to surgery, which could contribute to tumour dissemination in rectal neoplasias.

The aim of this study was to evaluate the relationship between the peripheral and mesenteric venous blood CEA levels and their putative association with the tumour location in the upper or lower rectum in surgically treated rectal carcinoma patients.

\section{METHODS}

Thirty-two rectal cancer patients who were surgically treated at Hospital Universitário São Francisco, Bragança Paulista, São Paulo, were analysed from August 2002 to April 2004. Adult patients of both genders with rectal carcinomas confirmed by histopathological examination were included. The exclusion criteria were the following: the presence of metastases detected upon preoperative analysis or surgical examination of the abdominal cavity; incomplete tumour removal; and current neoadjuvant chemoradiotherapy.

The patients were divided into two groups (A and B) according to the rectal tumour height measured by rigid proctosigmoidoscopy. Eleven (34.4\%) patients with tumours in the upper rectum (distal end of the tumour lesion $>10 \mathrm{~cm}$ from the anal margin) were allocated to group A. Twenty-one $(65.6 \%)$ patients with lower rectal tumours (lesion located $<10 \mathrm{~cm}$ from the anal margin) were placed in group B.

The peripheral venous blood was collected immediately following anaesthetic induction by percutaneous puncture of the patient's non-dominant upper-limb cephalic vein using a needle attached to a $10 \mathrm{~mL}$ syringe. The mesenteric venous blood collection was performed intraoperatively by puncture of the inferior mesenteric vein immediately following completion of the abdominal cavity inventory and prior to manipulating the rectal tumour.

The serum and mesenteric CEA levels were quantitatively assessed using a microparticle enzyme immunoassay kit ( $\mathrm{Ab}$ bott Laboratories, Abbott Park, Illinois, U.S.A.).
The CEA levels were assessed using the electrochemiluminescence immunoassay for in vitro quantitative assessment in human serum and plasma in immunoassay analysers. The recorded CEA levels in the peripheral and mesenteric venous blood were used to design the receiver operating characteristic (ROC) curve and determine sensitivity and specificity cut-offs.

The CEA indices, which represent the relationship between the mean upper limb CEA serum level and the mesenteric CEA level, of the upper and lower rectal tumours were assessed.

The preoperative peripheral CEA serum levels in the rectal carcinoma patients were assessed using the ROC curve: normal values $\leq 4.1 \mathrm{ng} / \mathrm{mL}$ and high values $>4.1 \mathrm{ng} / \mathrm{mL}$.

The intraoperative CEA levels in the inferior mesenteric vein, which were assessed using the ROC curve, were considered normal if they were $\leq 5.4 \mathrm{ng} / \mathrm{mL}$ and high if they were $>5.4 \mathrm{ng} / \mathrm{mL}$.

The serum CEA values in the upper-limb peripheral venous blood $(\leq 4.1 \mathrm{ng} / \mathrm{mL}$ or $>4.1 \mathrm{ng} / \mathrm{mL})$ and the CEA values in the inferior mesenteric vein $(\leq 5.4 \mathrm{ng} / \mathrm{mL}$ or $>5.4 \mathrm{ng} / \mathrm{mL})$ were compared according to the following variables: age $(<60$ and $\geq 60$ years), gender, ethnicity, presence or absence of a mucus-secreting tumour, tumour histological differentiation grade, depth of invasion into the intestinal wall, presence or absence of angiolymphatic invasion, TNM classification, and CEA index $(\leq 1.0$ or $>1.0)$.

The results are expressed as the mean and standard deviation. Qualitative variables are represented by the absolute $(\mathrm{N})$ and relative (percentage) frequencies. The Mann Whitney and Wilcoxon statistical tests were used to evaluate the results. The statistical analysis software used was SPSS version 15,0 (The Predictive Analytics Company, Chicago, IL, USA).

The ROC curve was designed to determine the cut-offs used to grade the upper limb and mesenteric vein CEA levels (Figure 1 and 2). Extremely high values were considered

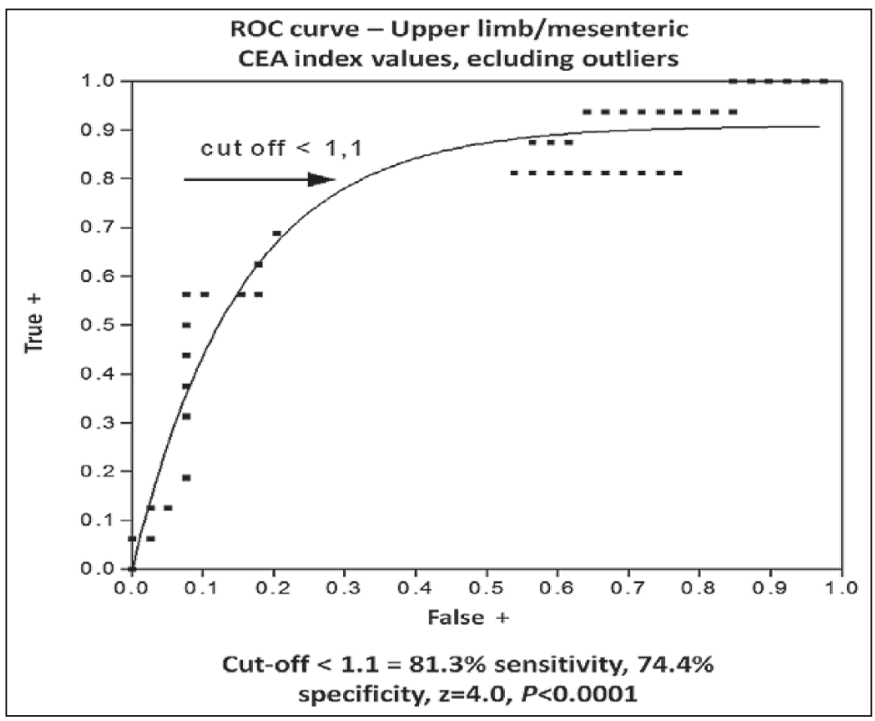

FIGURE 1. ROC curve indicating the upper limb CEA values CEA: carcinoembryonic antigen 


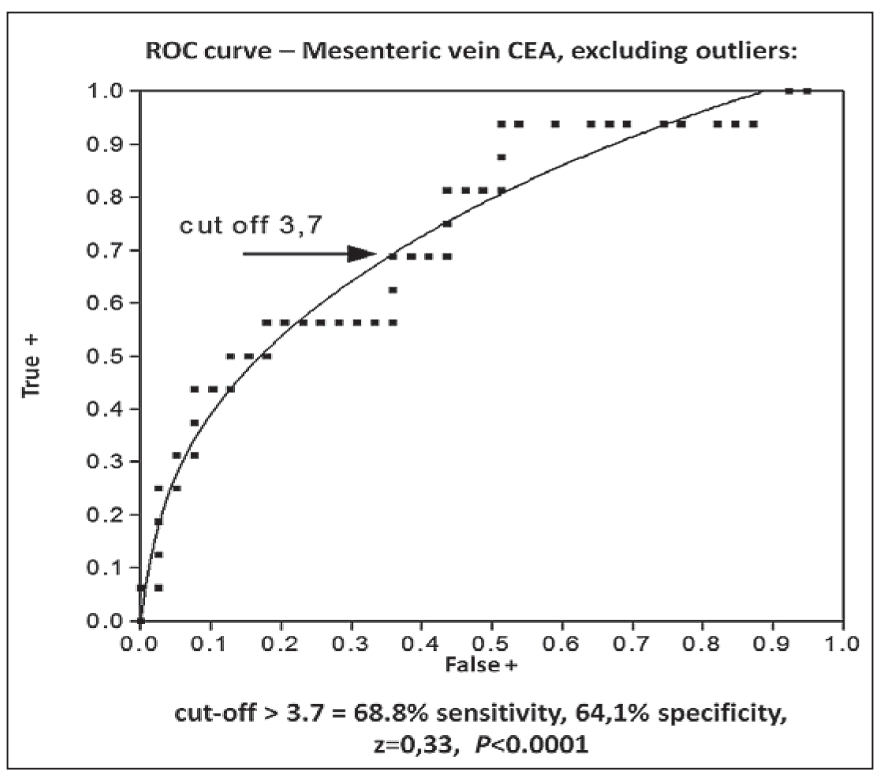

FIGURE 2. ROC curve indicating the inferior mesenteric CEA values CEA: carcinoembryonic antigen

outliers: values $>$ two standard deviations above or below the sample mean were excluded. The level for rejection of the null hypothesis was set at 5\% (95\% confidence interval [CI]) for all tests; asterisks $(*)$ indicate significant values. This study was conducted in accordance with the regulations of the Ethics in Human Research Committes at our Institution and in accordance with the ethical principles of the Declaration of Helsinki.

\section{RESULTS}

The mean CEA serum levels in the upper limb and inferior mesenteric venous blood of the lower rectal tumours were $4.59 \pm 4.16 \mathrm{ng} / \mathrm{mL}$ and $4.67 \pm 6.08 \mathrm{ng} / \mathrm{mL}$, respectively $(P=0.049)$. The peripheral serum level in the patients with upper rectal tumours was $9.74 \pm 9.27 \mathrm{ng} / \mathrm{mL}$, and in the inferior mesenteric vein was $11.46 \pm 10.21 \mathrm{ng} / \mathrm{mL}(P=0.031)$ (Table 1). The mean CEA levels in the peripheral blood in the upper and lower rectal tumours were $9.74 \pm 9.27 \mathrm{ng} / \mathrm{mL}$ and $4.59 \pm 4.16 \mathrm{ng} / \mathrm{mL}$, respectively $(P=0.12)($ Table 2$)$. The

TABLE 1. Mean levels of CEA in the upper-limb and inferior-mesenteric venous blood, according to the tumour location

\begin{tabular}{|c|c|c|c|}
\hline Location & & pper Limb & $P$-value \\
\hline Lower rectum & 4.59 & $\pm \quad 4.16 \mathrm{ng} / \mathrm{mL}$ & $0.049 *$ \\
\hline Upper rectum & 9.74 & $\pm 9.27 \mathrm{ng} / \mathrm{mL}$ & $0.031 *$ \\
\hline
\end{tabular}

* significant value

TABLE 2. Peripheral CEA values in venous blood collected from the upper limb, according to the tumour location

\begin{tabular}{lcc}
\hline Location & \multicolumn{3}{c}{ Upper Limb } \\
\hline Lower rectum & $4.59 \pm 4.16 \mathrm{ng} / \mathrm{mL}$ \\
Upper rectum & $9.74 \pm 9.27 \mathrm{ng} / \mathrm{mL}$ \\
\hline$P=0.12$
\end{tabular}

$P=0.12$ mean CEA level in the inferior mesenteric venous blood of the upper rectal tumours was $11.46 \pm 10.21 \mathrm{ng} / \mathrm{mL}$, and in the inferior mesenteric vein in the lower rectal tumours was $4.67 \pm 6.08 \mathrm{ng} / \mathrm{mL}(P=0.004)$ (Table 3$)$. The CEA indices of the upper and lower rectal tumours were $0.72 \pm 0.49 \mathrm{ng} / \mathrm{mL}$ and $1.66 \pm 1.60 \mathrm{ng} / \mathrm{mL}$, respectively $(P=0.0002)$ (Table 4$)$.

TABLE 3. Mesenteric CEA values according to the tumour location

\begin{tabular}{lc}
\hline Location & Mesenteric level \\
\hline Lower rectum & $4.67 \pm 6.08 \mathrm{ng} / \mathrm{mL}$ \\
Upper rectum & $11.46 \pm 10.21 \mathrm{ng} / \mathrm{mL}$ \\
\hline
\end{tabular}

$P=0.004$ significant value

CEA: carcinoembryonic antigen

TABLE 4. CEA index value according to the tumour location

\begin{tabular}{lcl}
\hline Location & & \\
\hline Lower rectum & $1.66 \pm 1.60 \mathrm{ng} / \mathrm{mL}$ \\
Upper rectum & $0.72 \pm 0.49 \mathrm{ng} / \mathrm{mL}$ \\
\hline
\end{tabular}

$P=0.002$ significant value

CEA: carcinoembryonic antigen

The comparison between the CEA serum values collected in the upper limb and the clinical and anatomopathological parameters of the rectal tumours revealed no significant association with age, gender, ethnicity, tumour location, histological type, cellular differentiation grade, depth of invasion into the intestinal wall, angiolymphatic invasion, or TNM staging.

The mesenteric CEA levels displayed an independent and significant association (odds ratio $=3.99 ; P=0.018 ; 95 \% \mathrm{CI}$, 1.26 to 12.65 ) with the tumour location, indicating that the probability of a CEA level $>5.4 \mathrm{ng} / \mathrm{mL}$ in the mesenteric veins of patients with upper rectal tumours is 3.99 times higher than in patients with lower rectal carcinomas.

A significant, independent relationship (odds ratio $=2.99$; $P=0.047 ; 95 \%$ CI, 1.01 to 8.87 ) was observed between the mesenteric CEA levels and the presence of angiolymphatic invasion, indicating that the probability of a CEA level $>5.4$ $\mathrm{ng} / \mathrm{mL}$ in the mesenteric blood is 2.99 times higher.

Logistic regression by multivariate analysis was performed for the CEA level in the inferior mesenteric vein blood, the rectal tumour location, and the presence of angiolymphatic invasion. The probability of measuring CEA levels $>5.4 \mathrm{ng} / \mathrm{mL}$ in the inferior-mesenteric venous blood was 3.36 times higher for the upper rectal tumours than for the lower rectal tumours (odds ratio $=3.36 ; P=0.045 ; 95 \%$ CI, 1.02-11.00). The presence of angiolymphatic invasion was not significant $(P=0.12)$.

The relation between the CEA index values and the tumour location in the upper or lower rectum was significant (odds ratio $=0.10 ; P=0.0001 ; 95 \% \mathrm{CI}, 0.02$ to 0.37 ). The probability that this index was $>1.0$ for a lower rectal tumour was $10 \%$ higher than for an upper rectal tumour. No significant difference was observed between the CEA index and the other clinical or anatomopathological parameters. 


\section{DISCUSSION}

Although TNM staging provides reliable prognostic information on rectal carcinoma, patients at the same stage may exhibit widely variable survival rates, particularly in TNM stages II and $\mathrm{III}^{(8,16)}$. Various prognostic factors, including molecular and biochemical markers (e.g., p53, K-ras, microsatellite instability, and tissue expression of thymidylate synthetase) have been analysed as adjuncts to the traditional TNM staging system to identify those patients with a high risk for tumour recurrence. However, the clinical application of these markers has not been widespread because the detection methods are complex and costly and the reference values vary ${ }^{(12)}$.

CEA is the most commonly used tumour marker for CRC because its assessment method is standardised, accessible, and affordable, motivating research studies on its preoperative prognostic ability and usefulness for postoperatively monitoring recurrence following curative surgery and evaluating the chemotherapy response $\mathrm{e}^{(12,15)}$.

Studies examining tumour marker samples collected from the peripheral or main drainage veins of colorectal tumours have revealed that these markers' levels are higher when the samples are collected from blood vessels near the tumour, suggesting that the marker levels in the peripheral vessels do not correspond to the total amount produced ${ }^{(7,17,18,20)}$. In this study, the CEA values in the inferior mesenteric vein were significantly higher than in the peripheral venous blood when the patients were considered as a single group.

The existence of factors that affect the systemic serum levels of CEA has been suggested, highlighting CEA production by tumour cells ${ }^{(19)}$, tumour marker excretion and passage through adjacent tissues ${ }^{(22)}$, the presence of tumour necrosis $^{(5)}$, the marker's ability to migrate into the blood and lymph stream, the formation of CEA-containing immune complexes, hepatic CEA metabolism, and CEA absorption by the colorectal mucosa ${ }^{(18)}$.

How CEA reaches the peripheral blood is not completely understood. The largest antigen contingent reaches the systemic circulation after passing through the portal system ${ }^{(18,20)}$. Previous studies ${ }^{(17,18)}$ have demonstrated that CEA produced by tumour cells preferentially reaches the systemic circulation by this pathway. The significant differences between the portal and peripheral CEA levels in the presence of venous tumour invasion and the greater depth of tumour invasion in the rectal wall support this possibility. CEA levels in the inferior mesenteric vein significantly increase following tumour manipulation during surgical resection ${ }^{(22)}$.

Tabuchi et al. ${ }^{(18)}$ correlated the levels of CEA in the peripheral and portal blood with the tumour histopathological variables in 66 CRC patients. They found that the average portal CEA level was significantly higher than the peripheral CEA level and was correlated with the presence of venous tumour invasion because CEA may undergo haematogenous drainage into the portal system through the tumour drainage vein. Similarly, high CEA levels are associated with venous invasion and the most advanced tumour stages. These authors noted that patients with high mesenteric CEA levels have increased risk for liver metastases and that high mesenteric CEA levels negatively impact survival.

Ivankovics et al. ${ }^{(7)}$ analysed the differences between the peripheral and mesenteric venous blood levels and cytokeratins in 138 surgically treated CRC patients. They found that the mesenteric CEA levels were highest in the subjects with advanced tumours exhibiting macroscopic vegetative characteristics and venous invasion. Cardoso et al. ${ }^{(3)}$ noted higher CEA levels in the mesenteric blood than in the peripheral blood in the largest tumours, in the presence of venous invasion, and at the later stages of the tumour, node, and metastasis (TNM) classification, in 169 surgically treated CRC patients.

The evaluation of mesenteric and peripheral CEA levels in CRC patients has revealed a higher index at stage IV of the TNM classification, especially as the tumour extends beyond the intestinal wall(7). Fernandes et al. ${ }^{(5)}$ reported a similar finding: increased CEA levels are related to occult metastases in the lymph nodes and/or liver parenchyma.

Waisberg et al. ${ }^{(20)}$ analysed a sample consisting of $28 \mathrm{CRC}$ patients and found increased CEA levels in the presence of venous invasion, suggesting that the portal drainage pathway is the main pathway for systemic distribution of the marker.

In the present study, when only rectal tumours were analysed, no correlation was found between the peripheral CEA values and angiolymphatic invasion. However, regarding the CEA values in the inferior mesenteric vein, the presence of lymphatic invasion is an independent variable for the high CEA levels in the main tumour drainage veins. The probability of finding CEA values $>5.4 \mathrm{ng} / \mathrm{mL}$ was 2.99 times higher in the presence of angiolymphatic invasion. The discrepancies between the CEA values may be attributed to hepatic metabolism of the marker and its inferior mesenteric level, which reduce the values in the peripheral venous vessels. However, Waisberg et al. ${ }^{(20)}$ found no difference between the mesenteric and peripheral CEA values, except in the presence of venous invasion. However, they failed to consider the different venous drainage pathways of upper and lower rectal tumours, which may have biased their results.

$\mathrm{Wu}$ et al. ${ }^{(24)}$ studied 56 patients who were surgically treated for middle and lower rectal carcinoma and found 7 $(12.5 \%)$ cases with local recurrence. They reported that high preoperative CEA levels and neoplasic venous emboli were significantly correlated with recurrence.

Several researchers have determined that high CEA serum levels prior to tumour resections are related to a higher recurrence index and, consequently, to the worst progno$\operatorname{sis}^{(7,17,18,23)}$. The serum CEA levels resulting from rectal tumours may vary according to the tumour's location. The rectum has vascular tributary drainage into two systems: portal and systemic. This venous drainage pattern is different from that in the colon, which occurs exclusively into the mesenteric vessels and subsequently into the liver via the portal vein, where CEA is metabolised by hepatocytes. The veins of the upper third of the rectum drain into the superior rectal vein, which drains into the portal system through the inferior mesenteric vein; conversely, the distal rectal veins 
drain into the middle and inferior rectal veins, tributaries of the internal iliac veins. These blood vessels drain directly into the systemic circulation ${ }^{(14)}$. The anastomoses between the two rectal venous drainage systems are controversial, and anatomical studies suggest extensive communication between the two systems ${ }^{(2)}$. The development of haemorrhoidal disease in patients with portal hypertension may prove the existence of this communication.

The distinct rectal venous-drainage routes may explain why tumours located in the distal rectum or anal canal usually cause systemic lung metastases without concomitant liver metastases ${ }^{(13)}$. Mitry et al. ${ }^{(11)}$ analysed lung metastases in CRC patients via a 30-year population study. They observed higher risk for lung metastases in rectal tumours than in colon tumours and suggested that rectal carcinoma patients should be submitted to the most specific screening tests to identify lung metastases.

In the present study, no significant difference was found when the peripheral CEA serum levels of patients with upper and lower rectal tumours were compared. However, the comparative analysis of the CEA levels in the inferior mesenteric vein revealed that the marker levels were significantly higher in the upper rectal tumours than in the lower rectal tumours. This difference may be explained by the partial drainage of CEA directly into the systemic circulation through the internal iliac veins.

These findings were confirmed by assessing the CEA index, which represents the ratio between the mean peripheral
CEA serum levels in the upper limb and the mean mesenteric CEA levels. The lower rectal CEA index values were determined to be significantly higher than those calculated for the upper rectal tumours, suggesting higher CEA drainage through the inferior mesenteric vein in the upper rectal tumours than the lower rectal tumours.

The results of the present study indicate that the rectum, unlike other colon segments, exhibits a peculiar venous drainage, which may influence changes in the CEA serum values based on the rectal tumour location. These findings may influence interpretations of the preoperative CEA assessment's validity as a prognostic factor in patients with rectal tumours. These different drainage pathways may be related to the dissemination pattern of neoplastic cells from the lower rectal tumours into the lung through the passage of neoplastic cells directly into the systemic venous drainage, thus bypassing the liver barrier. This phenomenon provides a plausible explanation for the higher incidence of brain or lung metastases from lower rectal tumours than from upper rectal and colonic tumours.

In conclusion, higher CEA levels in the inferior mesenteric vein in upper rectal tumours than those located in the lower rectum suggest that CEA drainage from the former preferentially occurs through the inferior mesenteric vein. Additionally, the presence of high CEA levels in the inferior mesenteric vein suggests the presence of angiolymphatic invasion, and CEA drainage from lower rectum adenocarcinomas preferentially occurs through the systemic pathway.

Rezende Jr HC, Palma RT, Toloi GC, Martinez CAR, Waisberg J. Niveis do antígeno carcinoembriônico no sangue venoso periférico e mesentérico em doentes com carcinoma retal. Arq Gastroenterol. 2013,50(4):264-9.

RESUMO - Contexto - O antígeno carcinoembriônico (CEA) sérico é um importante fator de prognóstico do câncer coloretal, contudo o reto apresenta diferentes vias de drenagem venosa, indicando que o nível do CEA periférico e mesentérico nos tumores retais podem ser diferentes, na dependência da localização da neoplasia no segmento retal. Objetivo - Avaliar em doentes operados curativamente de carcinoma do reto, a relação entre o nível venoso periférico e portal do CEA e a associação desses níveis com a localização da neoplasia no reto. Método - Trinta e dois doentes operados por carcinoma retal foram divididos em pacientes com tumores situados no reto alto $(n=11)$ e no reto baixo $(n=21)$. A análise dos valores de CEA foi determinada por imunoensaio de eletroquimioluminescência. As dosagens do CEA sérico e mesentérico foram associadas aos aspectos anatomopatológicos da neoplasia (localização da neoplasia, tipo histológico, grau de diferenciação celular, profundidade de invasão na parede retal, invasão angiolinfática); estadiamento tumor, nódulo e metástase e; ao índice do CEA ( $\leq 1,0 \mathrm{ou} \geq 1,0 \mathrm{ng} / \mathrm{mL}$ ). Resultados - A análise dos valores de CEA sérico com os parâmetros clínicos e anatomopatológicos não revelou associação significante com a localização do tumor, tipo histológico, grau de diferenciação celular, nível de profundidade de invasão na parede intestinal e estadiamento tumor, nódulo e metástase. Os valores dos níveis mesentéricos do CEA apresentaram associação significante com a localização do tumor $(P=0,010)$. Observou-se diferença significante entre os valores do CEA no sangue venoso mesentérico e a presença de invasão angiolinfática $(P=0.047)$. Encontrou-se relação significante entre o valor do índice de CEA e a localização do tumor no reto $(P=0,0001)$. Conclusão - Os níveis do CEA na veia mesentérica foram mais elevados nos tumores situados no reto superior e na presença de invasão angiolinfática. No adenocarcinoma do reto inferior, a drenagem do CEA ocorre preferencialmente por via sistêmica.

DESCRITORES - Neoplasias retais. Antígeno carcinoembrionário. Metástase neoplásica. 


\section{REFERENCES}

1. Bakalakos EA Jr, Burak WE, Young DC, Martin EW Jr. Is carcinoembryonic antigen useful in the follow up management of patients with colorectal liver metastases? Am J Surg. 1999;177:2-6.

2. Bernstein WC. What are hemorrhoids and what is their relationship to the portal venous system? Dis Colon Rectum. 1983;26:829-34.

3. Cardoso ML, Fernandes LC, Kim SB, Matos D. Relationship between peripheral and mesenteric serum levels of CEA and CA 242 with staging and histopathological variables in colorectal adenocarcinoma. Acta Cir Bras. 2009;24:405-10.

4. Duffy MJ, van Dalen A, Haglund C, Hansson L, Holinski-Feder E, Klapdor R, Lamerz R, Peltomaki P, Sturgeon C, Topolcan O. Tumour markers in colorectal cancer: European Group on Tumour Markers (EGTM) guidelines for clinical use. Eur J Cancer. 2007:43:1348-60.

5. Fernandes LC, Kim SB, Saad SS, Matos D. Value of carcinoembryonic antigen and cytokeratins for the detection of recurrent disease following curative resection of colorectal cancer. World J Gastroenterol. 2006;12:3891-4.

6. Harlozinska A, Rachel F, Gawlikowski W, Richter R, Kolodziej J. CEA and NCA levels in peripheral and tumour venous blood of patients with gastric and colonic carcinomas estimated by RIA and EIA methods. Eur J Surg Oncol. 1991;17:59-64.

7. Ivankovics IG, Fernandes LC, Saad SS, Matos D. Peripheral and mesenteric serum levels of CEA and cytokeratins, staging and histopathological variables in colorectal adenocarcinoma. World J Gastroenterol. 2008;14:6699-703.

8. Jass JR, Love SB, Northover JM. A new prognostic classification of rectal cancer. Lancet. 1987;1:1303-1306.

9. Jeffery GM, Hickey BE, Hider P. Follow-up strategies for patients treated for nonmetastatic colorectal cancer. Cochrane Database Syst Rev. 2002; doi:10.1002/14651858.CD002200.

10. Michels N, Siddarth P, Kornblith P. The variant blood supply to the descending colon, rectosigmoid, and rectum, based on 400 dissections. Dis Colon Rectum. 1965;8:251-78

11. Mitry E, Guiu B, Cosconea S, Jooste V, Faivre J, Bouvier AM. Epidemiology, management and prognosis of colorectal cancer with lung metastases: a 30-year population-based study. Gut. 2010;59:1383-8.

12. Park Y, Lee KY, Kim NK, Baik SH, Sohn SK, Cho CW. Prognostic effect of perioperative change of serum carcinoembryonic antigen level: a useful tool for detection of systemic recurrence in rectal cancer. Ann Surg Oncol. 2006;13:645-50.
13. Sakorafas GH, Zouros E, Peros G. Applied vascular anatomy of the colon and rectum: clinical implications for the surgical oncologist. Surg Oncol. 2006;15: 243-55.

14. Sudeck P. Über die Gefässversorgung des Mastdarmes in Hinsicht auf die operative Gangrän. München, Med Wchnschr. 1907;54:1314-7.

15. Sugarbaker PH, Gianola FJ, Dwyer A, Neuman NR. A simplified plan for follow-up of patients with colon and rectal cancer supported by prospective studies of laboratory and radiologic test results. Surgery. 1987;102:79-87.

16. Taal BG, Van Tinteren H, Zoetmulder FA. Adjuvant 5FU plus levamisole in colonic or rectal cancer: improved survival in stage II and III. Br J Cancer. 2001;85:1437-43.

17. Tabuchi Y, Deguchi H, Imanishi K, Saitoh Y. Carcinoembryonic antigen levels of peripheral and draining venous blood in patients with colorectal cancer: correlation with survival. Cancer. 1992;69:2411-7.

18. Tabuchi Y, Deguchi H, Imanishi K, Saitoh Y Comparison of carcinoembryonic antigen levels between portal and peripheral blood in patients with colorectal cancer: correlation with histopathologic variables. Cancer. 1987;59:1283-8.

19. Wagener C, Müller-Wallraf R, Nisson S, Gröner J, Breuer H. Localization and concentration of carcinoembryonic antigen (CEA) in gastrointestinal tumors: correlation with CEA levels in plasma. J Natl Cancer Inst. 1981;67:539-47.

20. Waisberg J, Contim-Neto L, Oliveira MS, Matheus C de O, Nagashima CA, Goffi FS. Determination of carcinoembryonic antigen levels in peripheral and draining venous blood in patients with colorectal carcinoma. Arq Gastroenterol. 2004:41:88-92.

21. Waisberg J, Palma RT, Contim-Neto L, Martins LC, Oliveira MSL, Nagashima CA, Godoy AC, Goffi FS. Biliary carcinoembryonic antigen levels in diagnosis of occult hepatic metastases from colorectal carcinoma. World J Gastroenterol. 2003;9:1589-93.

22. Wanebo JH. Cancer trends: the role of CEA in managing colorectal cancer. Va Med. 1983;110:103-8.

23. Wolmark N, Fisher B, Wieand HS, Henry RS, Lerner H, Legault-Poisson S, Deckers PJ, Dimitrov N, Gordon PH, Jochimsen P. The prognostic significance of preoperative carcinoembryonic antigen levels in colorectal cancer. Results from NSABP (National Surgical Adjuvant Breast and Bowel Project) clinical trials. Ann Surg. 1984;199:375-82.

24. Wu ZY, Wan J, Zhao G, Peng L, Du JL, Yao Y, Liu QF, Lin HH. Risk factors for local recurrence of middle and lower rectal carcinoma after curative resection. World J Gastroenterol. 2008;14:4805-9. 